\title{
Middle Childhood and Adolescent Contextual and Personal Predictors of Adult Educational and Occupational Outcomes: A Mediational Model in Two Countries
}

\author{
Eric F. Dubow \\ Bowling Green State University and University of Michigan \\ Paul Boxer \\ University of New Orleans and University of Michigan
}

\author{
L. Rowell Huesmann \\ University of Michigan
}

Lea Pulkkinen and Katja Kokko
University of Jyväskylä

\begin{abstract}
The authors examined the prediction of occupational attainment by age 40 from contextual and personal variables assessed during childhood and adolescence in 2 participant samples: (a) the Columbia County Longitudinal Study, a study of 856 third graders in a semirural county in New York State that began in 1960, and (b) the Jyväskylä Longitudinal Study of Personality and Social Development, a study of 369 eight-year-olds in Jyväskylä, Finland, that began in 1968. Both samples were followed up during adolescence and early and middle adulthood. Structural modeling analyses revealed that in both countries, for both genders, children's age 8 cognitive-academic functioning and their parents' occupational status had independent positive long-term effects on the children's adult occupational attainment, even after other childhood and adolescent personal variables were controlled for. Further, childhood and adolescent aggressive behavior negatively affected educational status in early adulthood, which in turn predicted lower occupational status in middle adulthood.
\end{abstract}

Keywords: family socioeconomic status, childhood aggression, childhood positive social behavior, adult educational attainment, adult occupational success

Career orientation is a critical component of successful functioning in adulthood (Caspi, Wright, Moffitt, \& Silva, 1998; Ja-

Eric F. Dubow, Department of Psychology, Bowling Green State University and Institute for Social Research, University of Michigan; L. Rowell Huesmann, Institute for Social Research, University of Michigan; Paul Boxer, Department of Psychology, University of New Orleans and Institute for Social Research, University of Michigan; Lea Pulkkinen and Katja Kokko, Department of Psychology, University of Jyväskylä, Jyväskylä, Finland.

Paul Boxer is now at the Department of Psychology, Rutgers University.

We are grateful to the Center for the Analysis of Pathways from Childhood to Adulthood, which is supported by the National Science Foundation (Grant 0322356), for research support for these analyses. The Columbia County Longitudinal Study has been supported by the Columbia County Tuberculosis and Health Association, Inc. (1960 data collection); the Hudson, New York, Lions Club (1960); the National Institute of Mental Health (1960, 1970, and 1981); and the National Institute of Child Health and Development (19992002, Grant HD36056). The Jyväskylä Longitudinal Study of Personality and Social Development has been funded by the Academy of Finland as a part of the project (Nos. 40166 and 44858) "Human Development and Its Risk Factors" (Finnish Centre of Excellence Programme, 1997-2005) and also in 1974-1975, 1979-1980, 1986-1989, and 1991-1996. Support also has been received from Finland's Cultural Foundation, 1986-1988; the Finnish Foundation for Alcohol Studies, 1986-1987 and 1996; the National Board of Health, 1981-1982 and 1986-1987; and the University of Jyväskylä.

Correspondence concerning this article should be addressed to Eric F. Dubow, Department of Psychology, Bowling Green State University, Bowling Green, OH, 43403. E-mail: edubow@bgnet.bgsu.edu hoda, 1981; Kokko, Pulkkinen, \& Puustinen, 2000; Warr, 1987) Pulkkinen, Ohranen, and Tolvanen (1999) conceptualized career orientation as a construct that includes multiple objective indices of an individual's work life, such as educational achievement, stability of career line, current work status, and current occupation. They are associated with indices of psychological functioning such as sense of coherence and self-esteem in middle age (Pulkkinen, Feldt, \& Kokko, 2006). On the contrary, researchers have found that unemployment across periods of early adulthood has negative effects on subsequent psychological well-being (e.g., life satisfaction, depressive affect; Feather \& O'Brien, 1986; Kokko et al., 2000; Warr \& Jackson, 1985).

Researchers have studied a variety of predictors of career orientation, including family of origin socioeconomic and process variables, personality traits and behaviors, academic achievement and motivation, and work-related attitudes (e.g., Caspi et al., 1998; Pulkkinen et al., 1999; Sanford et al., 1994; see Whitson \& Keller, 2004, for a comprehensive review of family of origin predictors), but only a few of these studies have followed individuals prospectively from childhood into middle adulthood. The present study examined personal and contextual factors from childhood and adolescence that predict adulthood educational and occupational attainment, using data from prospective studies in two countries: Finland (the Jyväskylä Longitudinal Study of Personality and Social Development [JYLS]; Pulkkinen, 1982; Pulkkinen, Feldt, \& Kokko, 2005) and the United States (the Columbia County Longitudinal Study [CCLS]; Eron, Walder, \& Lefkowitz, 1971; Hues- 
mann et al., 2002; Huesmann, Eron, Lefkowitz, \& Walder, 1984). We follow a developmental-contextual model to predict adulthood occupational status from family of origin socioeconomic status (SES), childhood cognitive-academic functioning, and childhood and adolescent social behaviors. We hypothesize that these variables affect middle adulthood occupational attainment both directly and through their effects on early adulthood educational attainment, and we examine the fit of this model across countries and gender.

\section{Early Life Course Contextual and Personal Predictors of Adult Education and Occupation}

Regarding contextual influences, results have confirmed that family SES predicts later educational attainment and occupational success (e.g., Caspi et al., 1998; Johnson et al., 1983; Stipek, 1998; Stipek \& Ryan, 1997). For example, Caspi et al. (1998) reported that lower parental occupational status of children ages 3-5 and 7-9 predicted a higher risk of the child having periods of unemployment when making the transition from adolescence to adulthood. Johnson et al. (1983) found that mothers' and fathers' educational level and fathers' occupational status were related positively to their children's adulthood occupational status. Numerous studies also have found that family SES (e.g., parental educational and occupational levels, family income) predicts children's educational attainment (e.g., Alexander, Entwisle, \& Bedinger, 1994; Davis-Kean, 2005; Duncan, Brooks-Gunn, \& Klebanov, 1994; Kokko et al., 2000; Luster, Rhoades, \& Haas, 1989; Smith, Brooks-Gunn, \& Klebanov, 1997; Stipek \& Ryan, 1997). Some of these studies have shown that family SES has direct effects on child academic achievement, whereas others have shown indirect effects through variables such as the intellectually and emotionally stimulating quality of the home environment, parents' expectations for their children's academic engagement, and stressors present in homes varying in socioeconomic levels.

In terms of the influence of the child's personal characteristics, empirical results have shown that childhood aggression and conduct problems precede subsequent difficulties in the domain of work, such as low education, unemployment, an unstable career line, and lower occupational status (Caspi et al., 1998; Fergusson, Horwood, \& Lynskey, 1997; Kokko \& Pulkkinen, 2000; Pulkkinen et al., 1999). On the other hand, social competence, constructive, and compliant behaviors in childhood have been linked to later success in the labor market, such as academic success, high career orientation, and a stable job (Pulkkinen, 1989, 2001; Pulkkinen et al., 1999; Shiner, Masten, \& Roberts, 2003; Werner \& Smith, 2001).

In their initial analyses of JYLS adult education and occupation data, Pulkkinen and colleagues (Kokko et al., 2000; Pulkkinen et al., 2006; Pulkkinen et al., 1999) have focused primarily on personal characteristics from childhood through adolescence that predict adult educational and occupational outcomes. Specifically, Pulkkinen (1996; L. Pitkänen, 1969) presented a model of behavioral and emotional regulation that conceptualized individual differences along two dimensions: (a) behavioral inhibition versus expression and (b) low versus high self-control of emotions. These two dimensions form four behavioral strategies that differ from each other along the two dimensions. Children with low self- control of emotions who are behaviorally passive exhibit anxious behavior; children with low self-control of emotions who are behaviorally active exhibit aggression. Children with high selfcontrol of emotions who are behaviorally passive exhibit compliant behavior; children with high self-control of emotions who are behaviorally active exhibit constructive social behavior. Pulkkinen et al. (1999) hypothesized that high self-control of emotions maintains internal arousal within an optimal range to facilitate academic, social, and work-related relationships, whereas low selfcontrol of emotions, especially if accompanied by high levels of behavioral activity (i.e., aggression), would hamper academic, social, and vocational pursuits. The results from their initial analyses of the JYLS data seemed to confirm these hypotheses.

\section{The Mediating Role of Educational Attainment in Predicting Adult Occupational Status}

Stipek (1998) has argued that the child's early academic achievement plays a central role in fostering continued academic achievement and educational attainment, which in turn influence successful pathways to adult functioning. Stipek's view is that initial academic and intellectual competence are related to children's motivation to succeed academically, their academic selfperceptions, their behavioral conduct, and teacher expectations and behaviors, all of which affect later educational attainment. Stipek noted that early academic problems can exacerbate externalizing behavior problems (see Hinshaw, 1992), which in turn influence the child's learning opportunities because children with behavioral problems often develop negative attitudes toward school and come into frequent conflict with teachers. Huesmann, Eron, and Yarmel (1987) presented analyses showing the reverse-namely, that early aggression impairs children's intellectual development over time. Both sets of findings underscore Stipek's (1998) assertion that childhood problem behavior and low academic functioning lead to "an increasingly stable spiral that becomes more and more difficult to escape" (p. 301).

In a Dunedin (New Zealand) sample, Caspi et al. (1998) tested the mediating effect of educational attainment during late adolescence on the relation of age 15 family contextual and personal factors to early adulthood unemployment. Although there was some attenuation of the effects of the predictor variables on unemployment once educational attainment had been entered into the analysis, several predictor variables (e.g., reading achievement, delinquency at age 15) retained significance, suggesting that these variables had direct effects on employment status that were not mediated by educational attainment. Kokko et al. (2000) found that low self-control of emotions (e.g., aggression) at age 8 had direct effects on long-term unemployment assessed between ages 27 and 36, whereas behavioral inhibition (e.g., passive and anxious behavior) at age 8 had indirect effects on unemployment through low academic achievement by ages 14 and 27. Kokko et al. also found that the relation between parental SES and the child's early adulthood unemployment was mediated by educational attainment at age 27 .

\section{The Present Study}

As described, there is an existing literature base on the developmental-contextual predictors of occupational outcomes 
into early adulthood, indicating that a variety of personal (e.g., educational attainment, behavioral regulation) and environmental (e.g., family of origin SES) factors account for those outcomes (Whitson \& Keller, 2004). However, there have been little data before now that allowed the extension of these analyses to predicting middle adulthood occupational success.

In this study, we examined the developmental-contextual view on the attainment of middle adulthood occupational status in the United States and Finland with longitudinal data sets spanning the time period from middle childhood to middle adulthood. Consistent with Stipek's (1998) ideas and converging findings reported by Caspi and others (e.g., Caspi et al., 1998), the overarching hypothesis of this investigation was that relations between childhood and adolescent contextual and personal variables and subsequent middle adulthood occupational attainment would be mediated by educational attainment in early adulthood. We expected that this mediational link would be produced in part by the behavioral and emotional regulatory tendencies that show continuity through childhood and adolescence and set the foundation for achievement in middle adulthood (cf. Pulkkinen, 1996).

Several unique features of the current study represent substantial contributions to the existing literature. First, although findings have been reported from a variety of countries separately, this study integrates data from the JYLS (Finland) and the CCLS (United States) in two-group structural models of occupational outcomes. This allows us to compare directly the developmentalcontextual prediction of outcomes in the two nations. Next, because both studies have collected extensive data on aggressive and positive social behaviors in childhood and adolescence, we were able to examine the relative and combined effects of both types of social behavior at both time points on subsequent occupational outcomes. Further, because both studies contain large numbers of male and female participants at each wave of data collection, we were able to consider the moderating role of gender in the developmental-contextual model of occupational outcomes from childhood to middle adulthood. Finally, given the broad time frame of both studies, we were able to consider whether educational attainment by early adulthood (allowing time for postsecondary studies) mediates the links between childhood and adolescent contextual and personal factors and occupational outcomes in middle adulthood.

\section{Method}

\section{Design of the CCLS}

The CCLS (Eron et al., 1971; Lefkowitz, Eron, Walder, \& Huesmann, 1977; Huesmann et al., 1984, 2002) began in 1960 and has culminated so far in the collection of four waves of data over a 40-year span on children who were living in Columbia County, New York, in 1960. The entire population of third graders (Generation 2 or G2; $N=856 ; 436$ boys, 420 girls) in the county participated in the first wave of this project in 1960 (Eron et al., 1971) when $85 \%$ of the participants' mothers and $71 \%$ of their fathers also were interviewed (Generation 1 or G1). Follow-up assessments were conducted in $1970(n=427), 1981(n=409)$, and most recently between 1999 and 2002 (Huesmann et al., 2002; $n=523$ ).

\section{Description of the CCLS Sample}

Columbia County, New York, is semirural with a few heavy industries. Of its approximately 63,000 current residents, about 7,500 live in the largest city and county seat, Hudson. The county has had a depressed economy for the last 50 years, although it has begun to benefit from the encroachment of the New York City metropolitan area. At the time the study began, there were 38 public and private third-grade classrooms in the county, all of which were included in the sample. Over $90 \%$ of the 856 participants in the original sample were Caucasian; $51 \%$ were male and 49\% were female. The number of ethnic minorities (i.e., 3\% African American, $<1 \%$ Asian or Pacific Islanders, $<1 \%$ Hispanic) was too small to allow separate analyses. The participants came from a broad range of socioeconomic backgrounds $(M=5.01, S D=2.23$, on a 10-point scale of father's occupational status derived by Eron et al., 1971, on the basis of Warner, Meeker, \& Eells's, 1960, 7-point scale; this mean reflects jobs such as craftsmen, foremen, and skilled tradesmen) and displayed a wide range of intelligence (mean IQ $=104, S D=14)$. The 427 participants (211 boys, 216 girls) who were reinterviewed in 1970 had a modal age of 19 years and had completed 12.6 years of education on average. In 1981, 409 of the original participants were reinterviewed (modal age $=30 ; 198$ men, 211 women). The average educational level of the sample was "some college or technical school," and the average verbal achievement, as indicated by an average of the spelling and reading scores on the Wide Range Achievement Test (WRAT; Jastak \& Jastak, 1978), was 96.34 $(S D=19.22)$, reflecting average achievement.

For the 523 participants (268 men, 255 women; $61 \%$ of the original sample) reinterviewed between 1999 and 2002, the mean age was 48.46 $(S D=0.77)$, the average education level was between some college and a college degree, the average occupational attainment was middle-class status (the average occupational prestige code using Stevens \& Hoisington's, 1987, prestige scores reflected jobs such as sales, bookkeepers, and secretaries), and $69 \%$ of the original participants were living with their spouses. The average verbal achievement score on the WRAT was 99.15 $(S D=13.72)$

\section{Attrition in the CCLS}

At age 48, we interviewed $61 \%$ (523) of the original sample of 856 . Of the noninterviewed participants, 37 were confirmed dead, 112 had disappeared and could not be found despite intense efforts, 40 could not be interviewed because of distance and scheduling difficulties, and 144 refused. The number who refused to be interviewed (despite substantial financial incentives) was higher than expected, but the completed reinterview rate of $61 \%$ over 40 years still provides us with a sizeable sample for analysis. However, we must ask whether the attrition introduced bias into the sample. A comparison of means on age 8 scores revealed that compared with participants who were reinterviewed at age 48, participants who were not reinterviewed had higher levels of aggression, $t(854)=4.06, p<.001$ $\left(M_{\text {difference }}=0.13, S E_{\text {difference }}=0.03\right)$; lower levels of popularity, $t(854)=$ $4.19, p<.001\left(M_{\text {difference }}=4.45, S E_{\text {difference }}=1.06\right)$; lower peer compliance, $t(854)=3.86, p<.001\left(M_{\text {difference }}=3.40, S E_{\text {difference }}=0.88\right)$, and lower IQ, $t(852)=5.69, p<.001\left(M_{\text {difference }}=5.70, S E_{\text {difference }}=\right.$ 1.00). These effect sizes range from $r=.14$ to $r=.19$. However, we note that the plots of the distributions for these four age 8 variables revealed that many of the high aggressive and low competent participants were resampled and there was no substantial restriction of range that might have made it hard to detect relations between these age 8 variables and adult outcomes. There was no significant difference in age 8 father's occupational status between resampled participants and dropouts.

\section{Procedures in the CCLS}

Data collection methods for the first three waves of the CCLS have been reported elsewhere (e.g., Eron et al., 1971; Lefkowitz et al., 1977; Huesmann et al., 1984, 2002). At age 8, two main sources of data were used: classroom-based peer nominations and extensive individual parent inter- 
views. At age 19, participants were administered a variety of self-report measures, as well as peer nominations, in individual interviews at a field office. At ages 30 and 48, interviews were conducted by computer in a field office and by mail or telephone for those participants who could not come to the office. At age 30, participants were paid $\$ 50$ for their participation; at age 48 , they were paid $\$ 100$ for their participation. Interviews ranged from 2 to $4 \mathrm{hr}$.

\section{Design of the JYLS}

The JYLS began in 1968 when 12 complete school classes of secondgrade pupils ( $N=369 ; 173$ girls, 196 boys) in the town of Jyväskylä, Finland, were randomly selected to be studied (Pulkkinen, 1982, 2004). Half of the classes were located in downtown Jyväskylä, a university and industrial town in central Finland with about 80,000 inhabitants, and half were in the suburban areas of Jyväskylä. The sample included 196 boys and 173 girls, all native Finns. The modal birth year was 1959 and the modal age was 8 years. Most of those original participants were followed at ages 14 (retention rate $=97 \%), 27(88 \%), 36(85 \%)$, and $42(83 \%)$. For the purposes of the present analyses, we focus on data from ages $8,14,27$, and 42 , to attempt to compute analyses for roughly similar developmental periods as the CCLS participants (i.e., ages 8, 19, 30, and 48). The predominant parental occupational status of the participants was bluecollar, whereas the participants themselves quite evenly distributed to blue-collar, lower white-collar, and upper white-collar occupations. The most typical occupational education for women was higher vocational school, whereas for men it was vocational school. Women had slightly more education than men in this sample, a finding obtained also in the entire Finnish age cohort born in 1959.

\section{Description of the JYLS Sample}

At age 14 (1974), 167 girls (97\% of the original sample) and 189 boys (97\%) were reinterviewed. At age 27 (1986), 155 women (90\%) and 166 men $(85 \%)$ completed a self-report questionnaire by mail, and 150 men (77\%) and 142 women (82\%) completed personal interviews. At age 42 (2001), the available sample size was reduced to 186 men (5 men had died and 5 had refused to participate) and 157 women (1 woman had died and 15 had refused to participate). At least some information was obtained from $85 \%$ of this sample.

\section{Attrition in the JYLS}

The attrition analyses at age 42 indicated that the participants and nonparticipants did not differ from each other in their social behavior (peer nominations) or academic success (teacher ratings) in childhood. Thus, the participants represent an unbiased resampling of the original random sample. In addition, the demographic characteristics of the JYLS sample were compared with those of the entire Finnish age cohort born in 1959 on the basis of data provided by Statistics Finland for this comparison on variables including marital status, number of children, education level, and employment rate; the JYLS sample was comparable to the entire birth cohort on these demographic indices (Pulkkinen et al., 2003).

\section{Procedures in the JYLS}

The methods of data collection at ages 8, 14, 27, and 42 have been reported elsewhere (e.g., Feldt, Kokko, Kinnunen, \& Pulkkinen, 2005; Pulkkinen, 2006; Pulkkinen et al., 2005). At ages 8 and 14, peer nominations of children's behavior were collected, and information about school achievement was obtained from teachers. At ages 27 and 42, the participants returned a mailed Life-Situation Questionnaire and completed selfreport inventories in person.

\section{Measures in the Two Studies}

Our goal was to select measures of the constructs of childhood and adolescent social behavior and adult educational and occupational outcomes that were as comparable as possible across the two studies.

\section{Childhood and Adolescent Measures}

Parents' occupation. In the CCLS, father's occupation was collected from parent interviews when the child was 8 years of age. We used an occupational coding scale developed by Warner et al. (1960) and adapted by Eron et al. (1971). Occupations were coded on a 10-point scale $(0=$ laborers to $9=$ professionals). At age 19 , the participants reported their father's occupation, which was coded using Warner et al.'s 7-point scale $(1=$ laborers to $7=$ professionals $)$. In the JYLS, parents' occupation at age 8 was provided by teachers and was coded on the basis of the father's occupation (or the mother's occupation, if she was a sole provider) on a 3 -point scale ranging from $1=$ blue-collar (cleaners, waiters) to $3=$ higher white-collar (managers, physicians; T. Pitkänen, Lyyra, \& Pulkkinen, 2005). Parents' occupational status during adolescence-early adulthood was assessed by a retrospective report by the participant at age 27 , when the participant was asked, "What has been your mother's and father's occupation?" It was coded as the higher occupational status of the two parents on a scale ranging from $1=$ blue-collar (cleaners, waiters) to $3=$ higher white-collar (managers, physicians; Feldt et al., 2005).

Child's cognitive-academic functioning. In the CCLS at age 8, child's cognitive-academic functioning was assessed with an IQ test, the California Short-Form Test of Mental Maturity (Sullivan, Clark, \& Tiegs, 1957). Kuder-Richardson reliability coefficients range from .87-.89 across grades; the total score correlates approximately .75 with other IQ measures. In the JYLS, teachers ranked students' academic achievement, separately by gender. The ranks were transformed into a 5 -point scale $(1=$ lowest ranking to $5=$ highest ranking; T. Pitkänen et al., 2005) that seems to reflect the child's intellectual abilities-that is, for a subsample of 60 boys, this measure correlated .70 with a standardized test of reading ability (L. Pitkänen, 1969).

Peer-nominated aggression. In the CCLS, peer-nominated aggression was assessed at ages 8 and 19 with a peer-nomination procedure developed by Eron et al. (1971), who defined aggression as "an act whose goal response is injury to another object" (p. 30). Their 10 peer-nominated aggression items cover physical (e.g., "Who pushes and shoves other children?"), verbal (e.g., "Who says mean things?"), acquisitive (e.g., "Who takes other children's things without asking?"), and indirect (e.g., "Who makes up stories and lies to get other children into trouble?") aggressive acts. The score represents the proportion of times the child was nominated by classmates on the 10 items (participants could nominate peers of either sex; thus, a child's score was the total number of nominations received across the 10 items divided by the number of classmates times 10). This measure is described in detail elsewhere (Eron et al., 1971; Huesmann et al., 1984), has been widely used, and has an alpha of .90 in cross-national samples, including the CCLS (Huesmann \& Eron, 1986).

At age 19, because participants would already have left high school, interviews were conducted in the field office. Participants first were presented with a list of those original participants who had attended school with them at age 8 and were asked to identify those whom they now know "well enough to answer some questions about." Aggression was measured using the same peer-nominated items as at age 8 , save for the omission of one item ("Who says, 'Give me that!'?"). Participants checked all the names that applied from the list of participants who fit each item. Each individual's score was computed as the number of times he or she was nominated on the nine questions divided by the number of times he or she could have been nominated (i.e., the number of participants who now knew the individual well). This measure was highly reliable $(\alpha=.90$ across the 
nine items). At ages 8 and 19, a log transformation was applied to the aggression scores to reduce skewness and kurtosis.

In the JYLS, at age 8, peer-nominated aggression was computed as an average score of 10 peer-nominated items (Kokko \& Pulkkinen, 2005) covering bullying (e.g., "Who attacks others without reason?"), physical (e.g., "Who hurts another child when angry, e.g., by hitting, kicking, throwing something?"), verbal (e.g., "Who says nasty things to other children even if they had done nothing wrong?"), and acquisitive (e.g., "Who takes other children's possessions?") aggressive acts. Peers nominated at least three same-sex children who behaved as described in the item. A child's score for each item was formed by the number of nominations received in the class in relation to the maximum number of votes (Pulkkinen, 1987). Cronbach's alpha was .90 for girls and .92 for boys. At age 14 , one compound item describing highly correlated aggressive acts that loaded highly on a general aggression factor (L. Pitkänen, 1969) was used: "Attacks without reason, teases others, says naughty things".

Peer-nominated positive social behavior. In the two studies, peernominated positive social behavior was assessed with two measures that we judged to reflect similar constructs: peer compliance and peer sociability.

In the CCLS, peer compliance was assessed at ages 8 and 19 with a two-item peer-nomination measure (Eron et al., 1971; i.e., "Who says 'excuse me' even when they have done nothing wrong?" and "Who will never fight even when picked on?"). Scores were computed similarly to the peer-nominated aggression measure. Cronbach's alpha was .67, and the measure has shown good validity (e.g., inverse relations to aggression and positive relations to popularity; negatively predictive of aggression over 30 years when composited with popularity; Eron \& Huesmann, 1984; Huesmann \& Eron, 1986). In the JYLS at age 8, peer compliance was measured by a three-item peer-nominated measure ("Who never quarrels with other children?"; "Who dislikes squabbling company and leaves it for something else?"; and "Who is peaceable and patient?"; Pulkkinen, 1982). Cronbach's alpha was .93 for girls and .89 for boys. At age 14, one peer-nominated item was used for peer compliance: "Who of your classmates are peaceable and patient, do not get involved in quarrels with others, are adjustable, and compliant?"

In the CCLS, peer sociability was assessed by a peer-nomination measure of popularity. This score represents the proportion of times the participant was nominated by classmates on two items: "Who would you like to have as a best friend?" and "Who would you like to sit next to in class?" Scores were computed similarly to the peer nomination of aggression score. Cronbach's alpha was .87; popularity scores correlate negatively with aggression (Eron et al., 1971). Although the JYLS did not include a popularity measure, to assess peer sociability at ages 8 and 14, the measure that was most comparable to popularity in the CCLS was the three-item peer-nominated constructiveness measure (e.g., "Who thinks that if one negotiates, everything will be better?"; "Who tries to act reasonably even in annoying situations?"; "Who sides with smaller and weaker peers?"; Pulkkinen, 1982). Cronbach's alpha was .82 for girls and .80 for boys. At age 14, one peer-nominated item was used for constructiveness: "Who of your classmates try to solve annoying situations reasonably, negotiate, conciliate, and strive for justice?"

Although the CCLS popularity measure and the JYLS constructiveness measure do not contain the same items, using a twin sample, Isomäki and Kukkonen (1993) found correlations of .68 for boys and .72 for girls between a peer-nomination measure of popularity similar to the CCLS measure and a slightly longer version of the JYLS constructiveness measure. It also should be noted that in the CCLS, peer nominations were solicited from the whole classroom (boys and girls), whereas in the JYLS, peer nominations were solicited from same-sex peers only. Although some researchers have observed bias against the opposite sex when using wholeclass nominations (e.g., Singleton \& Asher, 1977), others (e.g., Dubow, 1988; Terry \& Coie, 1991) have reported correlations above .80 between same-sex and entire-classroom nominations of aggression and sociability. This indicates that sex of nominator has minimal influence on a child's relative position within his or her sex.

\section{Adulthood Measures}

Educational status in early adulthood. In the CCLS, educational status in early adulthood was assessed at age 30 with a 7-point scale ranging from $1=$ did not finish high school to $7=$ doctorate or law degree. In the JYLS, at age 27, education was assessed with a 5-point scale ranging from $0=n o$ occupational education to $4=$ university degree.

Occupational status in adulthood. In the CCLS, occupational status in adulthood was assessed at age 48 with occupational prestige codes following Stevens and Hoisington (1987). Codes are provided for 889 specific occupations within 13 occupational categories (e.g., executive, administrative, and managerial; professional specialty; technicians; sales; protective service; mechanics/repairers; machine operators and inspectors). Higher codes indicate greater prestige. The codes range from 153 (ushers) to 810 (physicians). Two raters coded the participants' occupations. On a subsample of 162 occupations coded by each rater, the correlation between their assigned codes was .81 .

In the JYLS, at age 42, occupational status was coded into three categories, ranging from $1=$ blue-collar (e.g., cleaners, waiters) to $3=$ higher white-collar (e.g., managers, physicians). For further information, see Pulkkinen et al. (1999) and Pulkkinen et al. (2006).

\section{Results}

\section{Gender Differences in the Study Variables}

We computed $t$ tests to examine gender differences in the childhood, adolescent, and adult measures in each country. In the CCLS in the United States, there were no gender differences in age 8 cognitive-academic functioning or in age 8 or age 19 father's occupational status, but there were gender differences in the behavioral variables: Boys received higher levels of peer nominations for aggression than did girls at age 8, $t(854)=7.76, p<$ .001 , and at age $19, t(425)=7.81, p<.001$, and lower levels of peer compliance at age $8, t(854)=4.94, p<.001$. There were no gender differences in education by age 30 or occupation by age 48 .

In the JYLS in Finland, there also were no gender differences in age 8 adolescent-early adulthood parents' occupation. (Because teachers ranked age 8 cognitive-academic functioning separately by gender and because peer-nominated childhood and adolescent behavioral variables were restricted to same-sex peers, $t$ tests for gender differences in these variables were not computed.) In Finland, compared with men, women achieved higher levels of education during early adulthood, $t(346)=3.26, p<.01$. Women were more often in lower white-collar occupations than were men, whereas men were more often in blue-collar occupations (Pulkkinen et al., 2005). No differences existed in the higher white-collar occupations.

\section{Predicting Later Adulthood Occupational Status From Childhood and Adolescent Variables and Early Adulthood Educational Status}

Tables 1 and 2 show the correlations among the major study variables by gender in the CCLS in the United States (Table 1) and in the JYLS in Finland (Table 2). To examine further the relations of the childhood and adolescent variables to adulthood educational 
Table 1

Columbia County Longitudinal Study Correlations of Childhood and Adolescent Predictors of Adult Educational and Occupational Status

\begin{tabular}{|c|c|c|c|c|c|c|c|c|c|c|c|}
\hline Age and variables & 1 & 2 & 3 & 4 & 5 & 6 & 7 & 8 & 9 & 10 & 11 \\
\hline \multicolumn{12}{|l|}{ Age 8} \\
\hline 1. Father's occupation & - & $.13^{*}$ & .04 & .04 & .09 & $.58^{* *}$ & .13 & .14 & .00 & $.21^{*}$ & $.17^{*}$ \\
\hline 2. Child $\operatorname{cog} / \mathrm{acad}$ & .11 & - & $-.34 * *$ & $.31 * *$ & $.19 * *$ & .11 & $-.18^{* *}$ & $.15^{*}$ & $.14 *$ & $.29 * *$ & $.31 * *$ \\
\hline 3. Aggression & .04 & $-.27 * *$ & - & $-.40 * *$ & $-.35^{* *}$ & -.01 & $.42 * *$ & $-.19 * *$ & $-.30^{* *}$ & $-.31 * *$ & $-.17 *$ \\
\hline 4. Popularity & .09 & $.33 * *$ & $-.29 * *$ & - & $.64^{* *}$ & .10 & $-.19 * *$ & $.43^{* *}$ & $.17 *$ & $.16^{*}$ & $.16^{*}$ \\
\hline 5. Peer compliance & $.15^{*}$ & $.25^{\text {** }}$ & $-.48^{* *}$ & $.61 * *$ & - & .06 & $-.19 * *$ & $.30^{* *}$ & $.23 * *$ & $.14 *$ & .02 \\
\hline \multicolumn{12}{|l|}{ Age 19} \\
\hline 6. Father's occupation & $.55^{* *}$ & $.16^{*}$ & -.10 & $.16^{*}$ & $.19 * *$ & - & -.05 & $.14^{*}$ & .04 & $.28 * *$ & .12 \\
\hline 7. Aggression & -.03 & $-.16^{*}$ & $.41 * *$ & $-.14 *$ & $-.26^{* *}$ & -.19 ** & - & $-.25^{* *}$ & $-.38 * *$ & $-.25^{* *}$ & -.11 \\
\hline 8. Popularity & .04 & $.29 * *$ & -.10 & $.37 * *$ & $.19^{* *}$ & .12 & -.13 & - & $.42 * *$ & $.24 * *$ & .07 \\
\hline 9. Peer compliance & .08 & $.15^{*}$ & $-.36^{* *}$ & .13 & $.32 * *$ & .09 & $-.42 * *$ & $.17 *$ & - & $.29 * *$ & -.02 \\
\hline \multicolumn{12}{|l|}{ Age 30} \\
\hline 10. Education & .13 & $.32^{* *}$ & $-.29 * *$ & $.24 * *$ & $.35^{* *}$ & $.26^{* *}$ & $-.34 * *$ & $.30 * *$ & $.33^{* *}$ & - & $.29 * *$ \\
\hline \multicolumn{12}{|l|}{ Age 48} \\
\hline 11. Occupation & $.22^{* *}$ & $.29 * *$ & $-.27 * *$ & $.26^{* *}$ & $.30^{* *}$ & $.20 *$ & $-.32 * *$ & $.19^{*}$ & $.26^{* *}$ & $.59 * *$ & - \\
\hline
\end{tabular}

Note. Correlations for women are above the diagonal; correlations for men are below the diagonal. Sample sizes vary because of missing data. For women, sample sizes range from 138-420; for men, sample sizes range from 131-436. Child cog/acad = child's cognitive-academic functioning.

$* p<.05 . \quad * * p<.01$.

and occupational status, a series of four-group (U.S. men, U.S. women, Finnish men, and Finnish women) structural models were estimated with full information maximum likelihood estimation in Amos 6.01 (Arbuckle \& Wothke, 1999). ${ }^{1}$

The initial model hypothesized a fully mediated longitudinal structure in which occupational status from middle adulthood was predicted from educational level in early adulthood, and educational level in early adulthood was predicted from the three adolescent behavioral variables and parents' occupational status during adolescence-early adulthood. The three adolescent behavioral variables were predicted from the three childhood behavioral variables, along with the parents' occupational status at age 8 and the childhood cognitive-academic functioning variable. The parents' occupational status variable during adolescence-early adulthood was predicted from the parents' occupational status when the child was age 8 . These five independent variables from childhood were allowed to covary with each other. The four residuals associated with the four variables from adolescence also were allowed to covary with each other, but not with any of the other residuals. Likewise, the residuals associated with the educational and occupational status variables did not covary with any of the other residuals. Therefore, in this initial model there were no direct paths connecting the five variables from age 8 with either the educational or occupational variables from adulthood, nor were there any direct paths connecting the four variables from adolescence to the adulthood occupational status variable. The goodness-of-fit test statistics indicated that this initial hypothesized model was not very tenable for these data: Model $1, \chi^{2}(72, N=1,165)=179.01$, $p<.001$, root-mean-square error of approximation (RMSEA) $=$ .036. Consequently, in the next model, we added a direct path from childhood cognitive-academic functioning to early adult educational level. This model also was a rather poor, but improved, fit to these data: Model 2, $\chi^{2}(68, N=1,165)=138.53, p<.001$, RMSEA = .030; Model 1 versus Model $2, \chi^{2}(4, N=1,165)=$ $40.49, p<.001$. Thus, we further modified the model to include a direct path connecting the childhood cognitive-academic functioning variable to the adult occupational status variable and another direct path connecting parents' occupational status during adolescence-early adulthood to the adult occupational status variable. The fit of this model-Model 3, $\chi^{2}(60, N=1,165)=93.70$, $p=.004$, RMSEA $=.022$ - was a significant improvement over the previous model: Model 2 versus Model 3, $\chi^{2}(8, N=1,165)=$ $44.83, p<.001$. Finally, we added a direct path from each of the adolescent behavioral variables to adult occupational status. The resulting model was the most tenable-Model $4, \chi^{2}(48, N=$ $1,165)=72.34, p=.013$, RMSEA $=.021$, comparative fit index $=.99$-with a significant improvement in fit over the previous model: Model 3 versus Model $4, \chi^{2}(12, N=1,165)=$ 21.36, $p=.045$.

Three variations of Model 4 were then computed. In the first, we equated all of the path coefficients across genders within each country (i.e., U.S. women $=$ U.S. men and Finnish women $=$ Finnish men). This model provided a much worse fit to the data: Model 5, $\chi^{2}(102, N=1,165)=171.05, p<.001$, RMSEA $=$ .024; Model 5 versus Model 4, $\chi^{2}(54, N=1,165)=98.71, p<$ .001 . In the second model, we equated all of the path coefficients across countries within each gender (i.e., U.S. women $=$ Finnish women and U.S. men = Finnish men). The fit for this model was

\footnotetext{
${ }^{1}$ Prior to computing the structural models with the full information maximum likelihood (FIML) procedure, we removed 60 participants in the CCLS from the data set because they did not have an occupation code at age 48. These were participants who were interviewed at age 48 but indicated that they were not employed at that time for a variety of reasons (e.g., unemployed and seeking employment, retired, homemaker). Of course, they also are not included in the correlations for occupation in Table 1, but they would have been used by the FIML procedure for structural modeling if we had not explicitly removed them. In the JYLS, those participants who were not employed (e.g., unemployed, students) at age 42 were coded on the basis of their previous occupational status.
} 
Table 2

Jyräskylä Longitudinal Study of Personality and Social Development Correlations of Childhood and Adolescent Predictors of Adult Educational and Occupational Status

\begin{tabular}{|c|c|c|c|c|c|c|c|c|c|c|c|}
\hline Age and Variables & 1 & 2 & 3 & 4 & 5 & 6 & 7 & 8 & 9 & 10 & 11 \\
\hline \multicolumn{12}{|l|}{ Age 8} \\
\hline 1. Parents' occupation & - & $.22 * *$ & -.04 & .15 & .04 & $.75^{* *}$ & -.01 & -.07 & -.13 & $.33 * *$ & .16 \\
\hline 2. Child cog/acad & $.31 * *$ & - & -.13 & $.55 * *$ & $.37 * *$ & $.32 * *$ & -.07 & .12 & -.10 & $.34 * *$ & $.32 * *$ \\
\hline 3. Aggression & .00 & $-.18 *$ & - & $-.34 * *$ & $-.61 * *$ & -.06 & $.37 * *$ & .00 & $-.28 * *$ & -.11 & -.06 \\
\hline 4. Constructiveness & $.21^{* *}$ & $.54 * *$ & $-.23^{* *}$ & - & $.77 * *$ & $.21 *$ & -.12 & .11 & -.02 & $.23^{* *}$ & $.17 *$ \\
\hline 5. Peer compliance & .11 & $.30 * *$ & $-.57 * *$ & $.58 * *$ & - & .12 & $-.21 * *$ & .07 & $.23 * *$ & .11 & -.02 \\
\hline \multicolumn{12}{|l|}{ Age 14} \\
\hline 6. Parents' occupation & $.72 * *$ & $.34 * *$ & -.07 & $.18 *$ & .11 & - & -.06 & -.08 & -.11 & $.37 * *$ & .17 \\
\hline 7. Aggression & -.12 & -.07 & $.36^{* * *}$ & $-.20 * *$ & $-.36 * *$ & -.11 & - & -.10 & $-.40 * *$ & $-.19^{*}$ & .01 \\
\hline 8. Constructiveness & -.04 & .06 & $-.26 * *$ & $.29 * *$ & $.31 * *$ & -.01 & $-.26^{* *}$ & - & $.29 * *$ & .10 & $.21 *$ \\
\hline 9. Peer compliance & -.12 & -.03 & $-.29 * *$ & .12 & $.33 * *$ & -.08 & $-.40 * *$ & $.60 * *$ & - & -.03 & -.17 \\
\hline \multicolumn{12}{|l|}{ Age 27} \\
\hline 10. Education & $.34 * *$ & $.35 * *$ & -.13 & $.32 * *$ & $.23 * *$ & $.29 * *$ & -.13 & .15 & .00 & - & $.47 * *$ \\
\hline \multicolumn{12}{|l|}{ Age 42} \\
\hline 11. Occupation & $.38 * *$ & $.45^{* *}$ & -.12 & $.30 * *$ & $.20 *$ & $.35 * *$ & -.08 & .03 & -.12 & $.53^{* *}$ & - \\
\hline
\end{tabular}

Note. Correlations for women are above the diagonal; correlations for men are below the diagonal. Sample sizes vary because of missing data: For women, sample sizes range from 126-173; for men, sample sizes range from 144-196. Child cog/acad = child's cognitive-academic functioning.

$* p<.05$. $* * p<.01$.

also much worse: Model $6, \chi^{2}(102, N=1,165)=187.17, p<$ .001, RMSEA $=.027$; Model 6 versus Model $4, \chi^{2}(54, N=$ $1,165)=114.83, p<.001$. Finally, we equated all of the path coefficients across all four groups (i.e., U.S. men $=$ U.S. women $=$ Finnish men $=$ Finnish women). This model too produced an overall poorer fit: Model 7, $\chi^{2}(129, N=1,165)=244.79, p<$ .001 , RMSEA $=.026$; Model 7 versus Model $4, \chi^{2}(81, N=$ $1,165)=172.45, p<.001$. Therefore, the best fitting model retained for these data was the one in which the path coefficients were free to vary across country and gender (Model 4).

Figures 1-4 display estimated standardized path coefficients from the final model for CCLS women, CCLS men, JYLS women, and JYLS men, respectively. The path coefficients shown represent standardized direct effects of one variable on another. ${ }^{2}$

These results show that for all four groups, there was continuity in aggression from childhood to adolescence; for all groups but U.S. women, there was continuity in peer compliance from childhood to adolescence; for all groups but Finnish women, there was continuity in popularity-constructiveness from childhood to adolescence; and for all groups, parental occupational status was highly stable from age 8 to adolescence-early adulthood. However, parental occupational status had no significant direct effect on the child's occupational status at age 48 for any of the groups (though there was a marginal effect for men in Finland). In all groups, parental occupational status strongly predicted higher educational status for the child during early adulthood, which in turn strongly predicted higher occupational status for the child in middle adulthood, but parent occupational status had no other direct effect on adult occupational status.

The model also revealed unique direct effects of adolescent behaviors on the child's later educational and occupational status. Specifically, popularity-constructiveness in adolescence predicted higher educational status in young adulthood especially for boys; adolescent aggression predicted lower educational status for most groups; and peer compliance in adolescence predicted higher ed- ucational status for U.S. men. However, peer compliance predicted lower occupational status in middle adulthood for most groups. Finally, for all groups, age 8 child cognitive-academic functioning had significant direct effects on young adult educational status and, for all groups except U.S. men, had significant direct effects on occupational status in middle adulthood in addition to its effects mediated through educational status and independently of the effects of parents' occupational status and the child's social behaviors that are in the model.

Putting the above paths together, we can recognize a number of important mediated paths from childhood and adolescent variables to adult occupational status. In fact, with the exception of childhood cognitive-academic functioning, most of the effects of childhood and adolescent variables on occupational status in middle adulthood are mediated through educational status in young adulthood. This is true for parents' occupational status, for childhood aggression, and for peer popularity-constructiveness. Only peer compliance seems to have reliable nonmediated effects on adult occupational status, and those effects are negative.

\section{Discussion}

In this study, we applied a general developmental-contextual model to predict middle adulthood occupational outcomes using prospective longitudinal data collected in the United States and Finland. We were guided by a framework describing the role of educational achievement in linking child and adolescent contextual (i.e., family SES) and personal (i.e., cognitive-academic functioning, social behavior) factors to later educational and occupational attainment (e.g., Caspi et al., 1998; Stipek, 1998).

\footnotetext{
${ }^{2}$ Tables showing the computed standardized indirect effects for each path in the model and the standardized total effects along with the squared multiple correlations are not included because of space limitations but can be obtained by contacting Eric F. Dubow.
} 


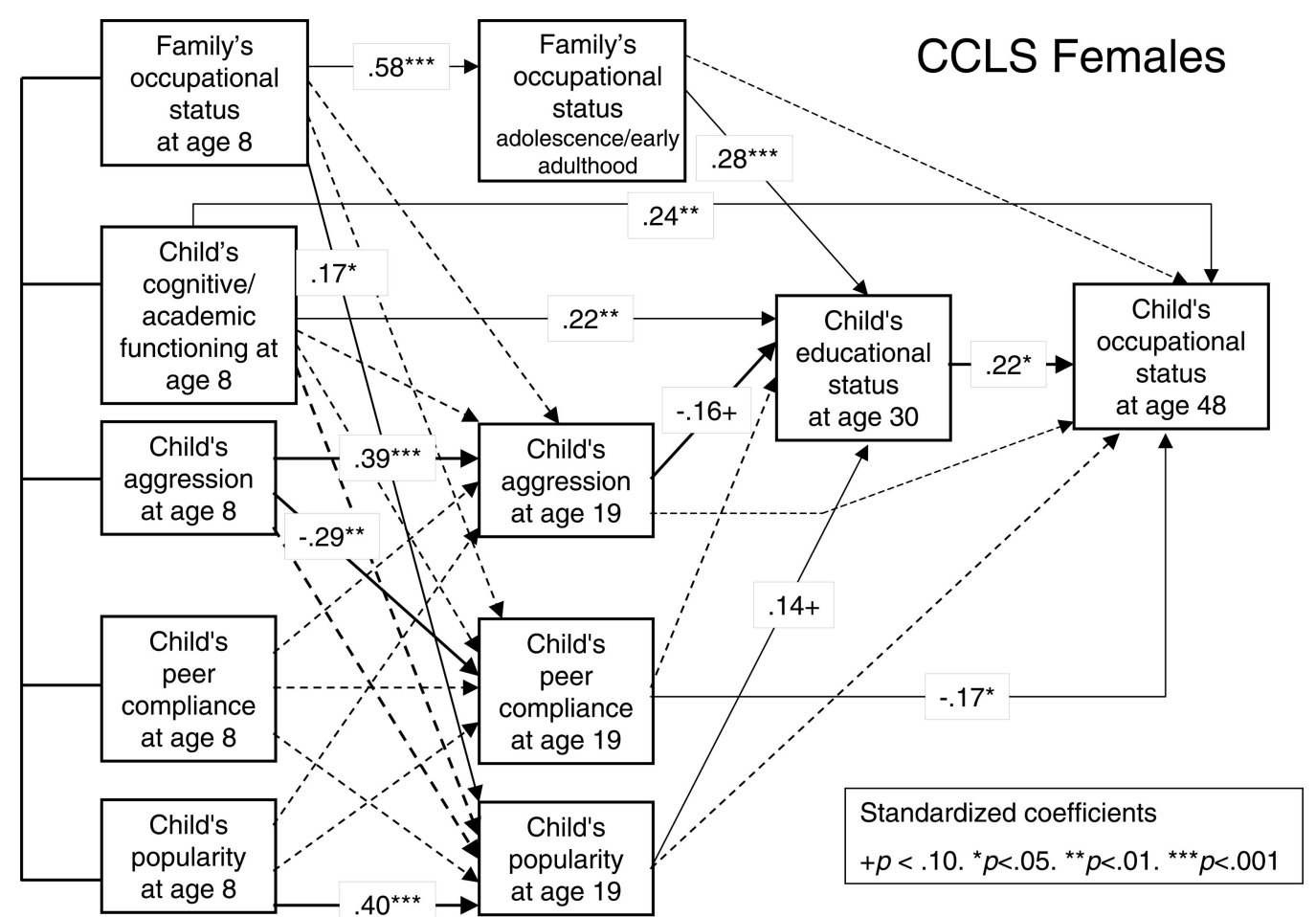

Figure 1. Estimated standardized coefficients from Model 4 for women in the Columbia County Longitudinal Study (CCLS). All numeric values represent the estimated standardized path coefficients. Estimated paths that were not statistically significant at the .10 level are represented by dashed lines. The residual terms from the predictors, the estimated correlations between these residuals, the estimated correlations between the exogenous variables, and the estimated means have all been omitted for clarity of presentation.

\section{Family SES as a Predictor of Adult Outcomes}

The effects of family SES in childhood (i.e., parental occupational status) on adult outcomes at ages 27 or 30 and 42 or 48 were almost fully mediated in all four groups by continuity in SES from childhood to adolescence-early adulthood. Further, in all four groups, family SES predicted adult occupational success indirectly through educational attainment by age 27 or 30 . It is important to note that in all groups but Finnish men, family SES predicted adult occupational status only indirectly. For the Finnish men, family SES had a direct effect on adult occupational status in addition to the indirect effect through adult educational attainment.

Of interest, in all groups but Finnish women, family SES in childhood predicted adult outcomes indirectly through adolescent positive social behavior variables. Family SES at age 8 predicted adult educational attainment indirectly through popularity at age 19 for U.S. women and through peer compliance at ages 14 and 19 for Finnish and U.S. men, respectively. Surprisingly, we observed no indirect effects of family SES on adult outcomes through adolescent aggression. Although developmental scholars have shown evidence for the far-reaching effects of childhood SES (cf. Leventhal \& Brooks-Gunn, 2000; McLoyd, 1998), much empirical research and theorizing has focused on the potential long-term consequences of social-economic disadvantage for aggression and other forms of maladjustment (e.g., family-stress models; Conger, Patterson, \& Ge, 1995). Of course, higher family SES covaries with cognitive-academic functioning (see
Tables 1 and 2) and can serve an important positive socialization function in regard to longer term educational and vocational success (Davis-Kean, 2005; Eccles, 1993). However, our model did not include other familial (e.g., parenting variables, family stressors) and nonfamilial factors (e.g., neighborhood and school characteristics) that might covary with SES and child adjustment and also affect adult educational and occupational outcomes. But our findings do suggest that family SES in childhood might have long-term effects through a direct relation to child and adolescent social behavior in addition to its continuity with family SES in adolescence-early adulthood.

\section{Childhood and Adolescent Personal Variables as Predictors of Adult Outcomes}

For all four of the participant groups, cognitive-academic functioning in middle childhood related positively to adult educational and occupational success. For both genders in Finland and for women in the United States, cognitive-academic functioning had direct and indirect effects on educational and occupational status, but for men in the United States, this variable had a direct effect only on educational status, which in turn predicted later occupational success. Across groups these effects were quite robust in that they retained statistical significance even when modeled simultaneously with family SES during childhood and adolescence and with a variety of concurrent childhood and intervening adolescent variables. 


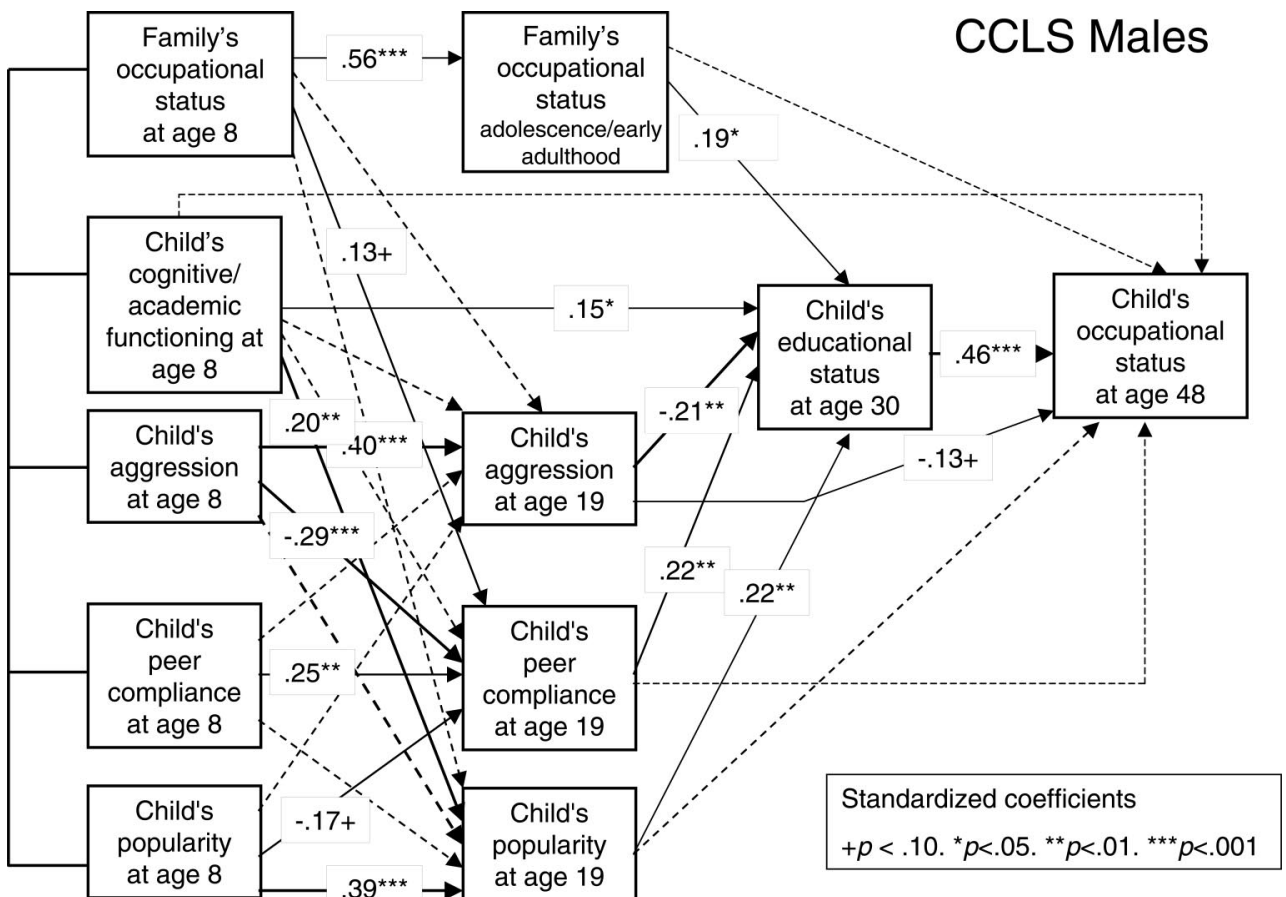

Figure 2. Estimated standardized coefficients from Model 4 for men in the Columbia County Longitudinal Study (CCLS). All numeric values represent the estimated standardized path coefficients. Estimated paths that were not statistically significant at the .10 level are represented by dashed lines. The residual terms from the predictors, the estimated correlations between these residuals, the estimated correlations between the exogenous variables, and the estimated means have all been omitted for clarity of presentation.

Developmental scholars have emphasized the importance of middle childhood in shaping adult outcomes (cf. Huston \& Ripke, 2006), as this period is a critical time, especially in regard to cognitive skill acquisition (e.g., Piaget, 1965). Thus it is not surprising that our measures of participants' cognitive-academic functioning retained predictive value through adulthood, especially given typical observations of high stability in intellectual functioning (e.g., Jimerson, Egeland, Sroufe, \& Carlson, 2000). Our findings add to the validity of these observations by confirming longterm effects into adulthood across genders in two countries.

For all participant groups, we observed partial mediation of links between adolescent behaviors and middle adulthood occupational attainment through early adulthood educational achievement. Regarding aggressive behavior, for all groups except men in Finland, more aggressive children and adolescents attained lower levels of education by young adulthood independently of their middle childhood cognitive-academic functioning and parents' occupational status. In turn, this lower educational attainment predicted lower occupational success. For all four groups, constructive behavior-popularity during adolescence predicted adult occupational success indirectly through higher levels of early adulthood educational attainment (all groups except Finnish women) or directly (Finnish women). Peer compliance during adolescence predicted lower levels of adult occupational status for all groups except U.S. men.

Overall, the findings for the indirect and direct effects of social behaviors are consistent with Pulkkinen's (1996) and Stipek's
(1998; also see Huesmann, Eron, \& Yarmel, 1987) views on how childhood and adolescent social behaviors account for long-term adult outcomes. Generally, their theories propose that social and behavioral difficulties in childhood impair subsequent academic achievement by interfering with learning and limiting opportunities for success. Our results support Pulkkinen's (1996) model of emotional and behavioral regulation in that key indicators of those constructs (i.e., aggression, peer compliance, and constructiveness) generally showed continuity through childhood and adolescence and accounted for variance in early adulthood educational attainment, which in turn linked those indicators to middle adulthood occupational success. The mediational function of early adulthood educational achievement-confirmed for all groups-is consistent with Stipek's (1998) assertion that early behavioral styles create an "increasingly stable spiral" (p. 301) of salient adult outcomes.

\section{Similarities Across Groups: Implications for Construct Validity}

Our findings reveal general similarities across the four subgroups (two genders in each of the two countries). Perhaps most important, the results of the model fitting provided support for our overarching theoretical view regarding the long-term effects of childhood contextual and personal factors and the mediational function of educational attainment prior to middle adulthood. Although the strengths of path coefficients and the specific variables accounting for links between time points varied somewhat 


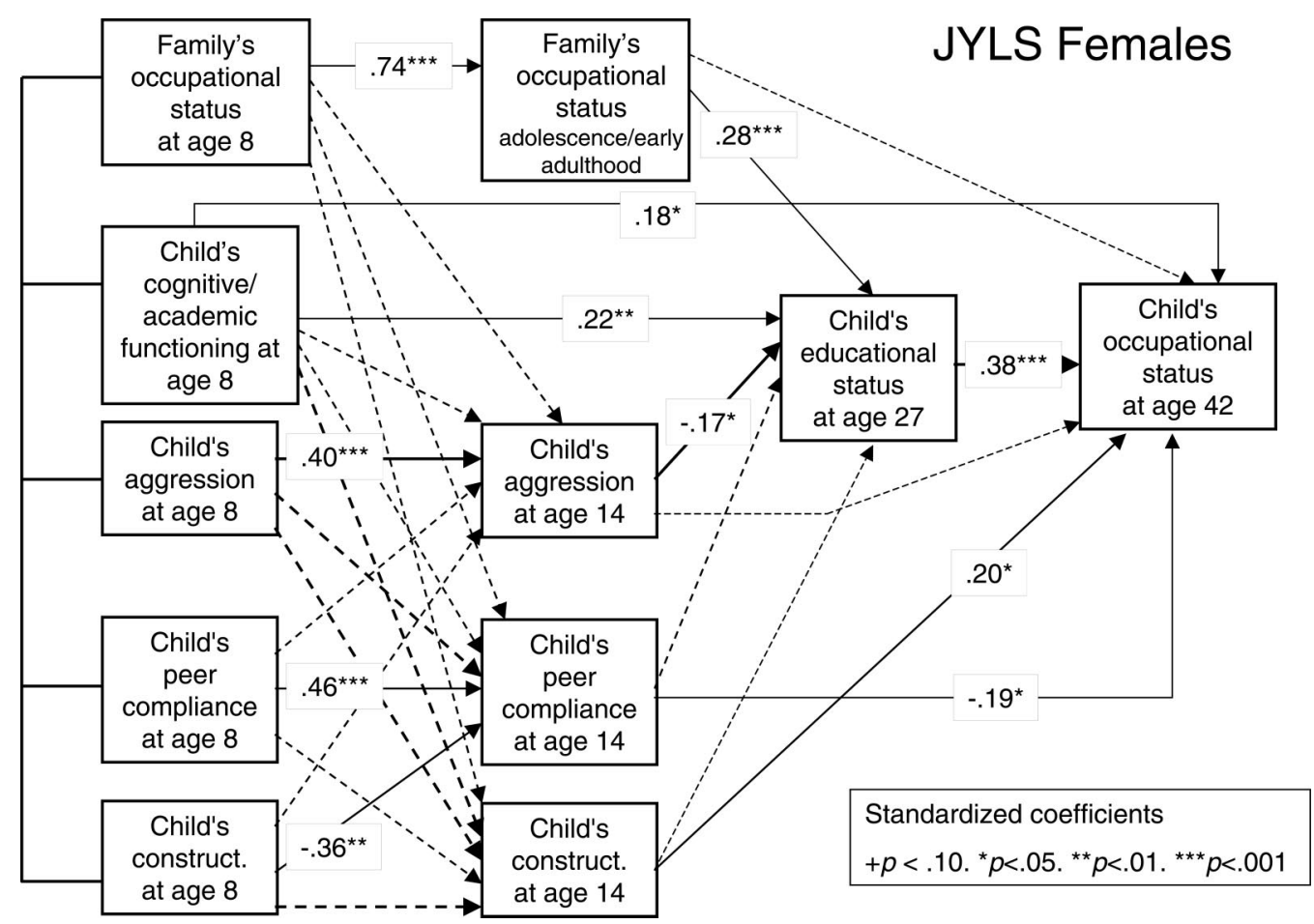

Figure 3. Estimated standardized coefficients from Model 4 for women in the Jyväskylä Longitudinal Study of Personality and Social Development (JYLS). All numeric values represent the estimated standardized path coefficients. Estimated paths that were not statistically significant at the .10 level are represented by dashed lines. The residual terms from the predictors, the estimated correlations between these residuals, the estimated correlations between the exogenous variables, and the estimated means have all been omitted for clarity of presentation. construct. $=$ constructiveness.

from group to group, the general similarities in findings and variable structures across groups were fairly striking. These similarities are even more impressive when one keeps in mind the differences in the measures between countries. Cognitiveacademic functioning was assessed by a standardized IQ test in the United States and by a teacher rating scale in Finland. Adolescent behaviors were assessed at age 19 in the United States and age 14 in Finland. Behavioral measures in childhood and adolescence relied on somewhat different items assessing broader constructs. Perhaps the largest difference in measures between countries was for the peer sociability indices. The constructive behavior measure used in Finland (derived from Pulkkinen et al.'s, 1999, model) describes sociable children who aim to construct social situations to meet the needs of the partners involved. Although this is not the same as the U.S. popularity measure, constructive behavior makes children popular, as shown by the high correlation between constructiveness and popularity (Isomäki \& Kukkonen, 1993).

It is important to consider measurement in this investigation with respect to theories of measurement validity. The traditional approach to asserting the validity of a measure requires attention to content (i.e., the items adequately sample the universe of items describing the construct in question), criterion (i.e., the measure adequately predicts or correlates with meaningful performance criteria), and construct (i.e., the measure adequately assesses the theoretical construct) validity (Anastasi \& Urbina, 1997). The fact that the CCLS and JYLS were conducted independently precluded us from ensuring complete content validity across the two data sets; optimally, we would have identical measures of each construct. Still, our findings demonstrate criterion validity (i.e., similar, significant, and meaningful prediction of educational and occupational outcomes) for our measurement strategy.

Our results also indicate construct validity. This form of validity is particularly important to consider here given our interest not only in asserting the generalizability of our findings across two countries but also in examining the extent to which our results conform to relevant developmental theory. The comparison between analytic results and extant theory is the central purpose of determining construct validity (cf. Cronbach \& Meehl, 1955; also see Messick, 1995). Thus it is worth emphasizing that whereas our items tapping similar constructs (e.g., positive social behavior) vary across data sets, the results of model fitting indicate that the measures operate similarly across data sets. Content validity in practice really is just one of several different ways of demonstrating construct validity (Messick, 1995), and the substantive theoretical and empirical evidence of construct validity (for individual constructs as well as the broader model) in our investigation lends additional weight to our findings even in the context of item variation across data sets. 


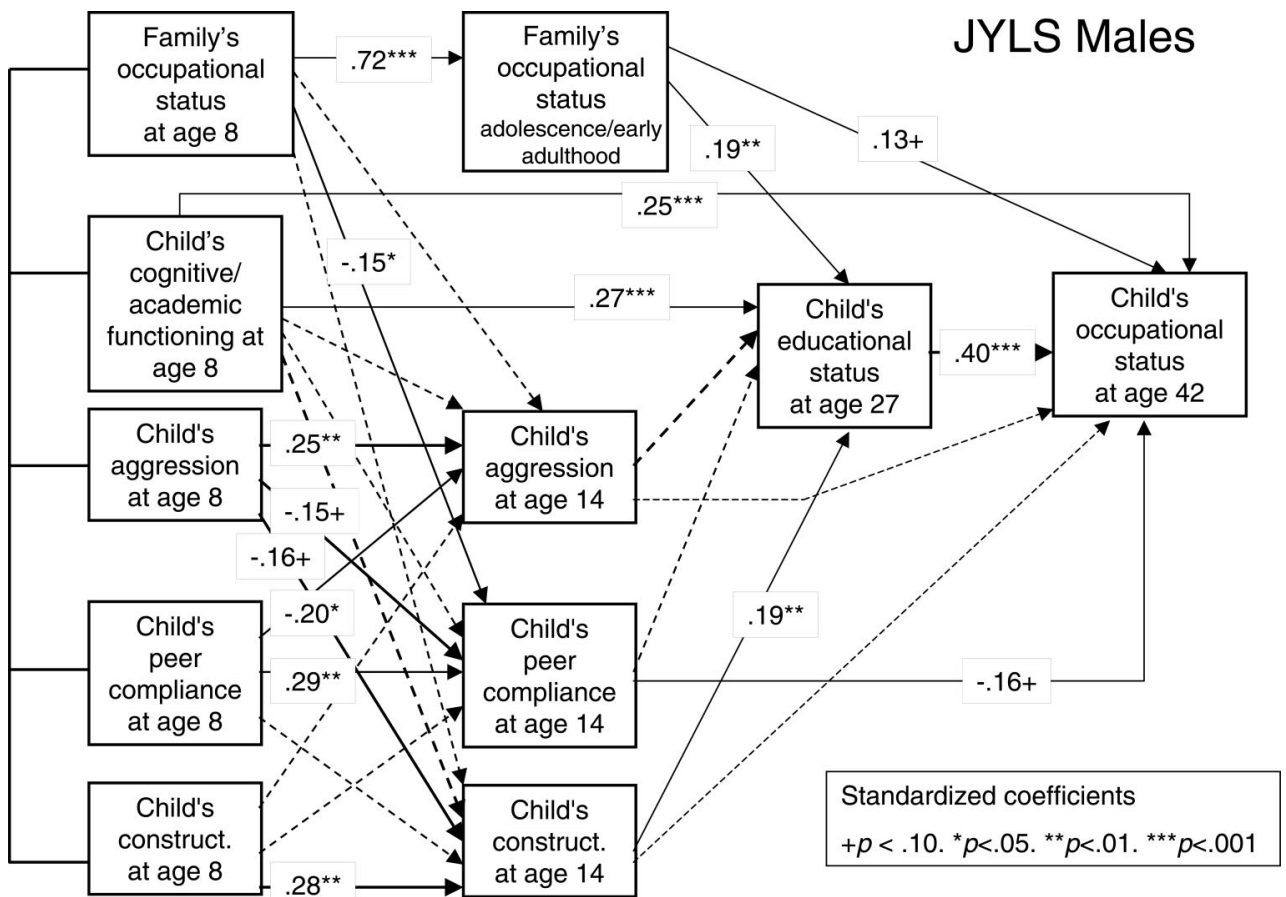

Figure 4. Estimated standardized coefficients from Model 4 for men in the Jyväskylä Longitudinal Study of Personality and Social Development (JYLS). All numeric values represent the estimated standardized path coefficients. Estimated paths that were not statistically significant at the .10 level are represented by dashed lines. The residual terms from the predictors, the estimated correlations between these residuals, the estimated correlations between the exogenous variables, and the estimated means have all been omitted for clarity of presentation. construct. $=$ constructiveness.

\section{Conclusion}

Our major findings revealed that in both the United States and Finland, for both genders, children's age 8 cognitive-academic functioning and their parents' occupational status from childhood to adolescence had independent positive direct and indirect effects on the children's adult educational and occupational attainment, even after we controlled for other childhood and adolescent personal variables. In addition, childhood and adolescent social behavior was related to educational status in early adulthood, which in turn predicted occupational status when the participants were in their 40s. The long-term independent effect of the family of origin's SES is not surprising. From a social capital perspective (Eccles, Templeton, Barber, \& Stone, 2003), it is possible that parents with higher SES provided tangible opportunities for their children's vocational development (e.g., business opportunities, connections to jobs in the community through their own personal networks). Perhaps these parents also held higher occupational aspirations for their children, which their children internalized, thus playing the role of "expectancy socializers" (see Eccles, 1993). Those findings have implications for targeting social policy initiatives to enhance parental SES when children are young (Magnuson, 2004; Morris \& Michalopoulos, 2003), especially given the rather substantial continuity of family SES observed in our data across countries. Also noteworthy are the long-term negative effects of childhood and adolescent aggression on adult educational and occupational success and the long-term positive effects of childhood and adolescent positive social behaviors on adult educational and occupational success. Those findings underscore the need for early intervention programs to mitigate aggression and promote social competence in the service of preventing school dropout and vocational underachievement (Battin-Pearson et al., 2000; Weissberg, Caplan, \& Harwood, 1991).

\section{References}

Alexander, K. L., Entwisle, D. R., \& Bedinger, S. D. (1994). When expectations work: Race and socioeconomic differences in school performance. Social Psychology Quarterly, 57, 283-299.

Anastasi, A., \& Urbina, S. (1997). Psychological testing (7th ed.). Upper Saddle River, NJ: Prentice Hall.

Arbuckle, J. L., \& Wothke, W. (1999). Amos users' guide (Version 4.0). Chicago: Small Waters.

Battin-Pearson, S., Abbott, R. D., Hill, K. G., Catalano, R. F., Hawkins, J. D., \& Newcomb, M. D. (2000). Predictors of early high school dropout: A test of five theories. Journal of Educational Psychology, 92, $568-582$.

Caspi, A., Wright, B. R. E., Moffitt, T. E., \& Silva, P. A. (1998). Early failure in the labor market: Childhood and adolescent predictors of unemployment in the transition to adulthood. American Sociological Review, 63, 424-451.

Conger, R. D., Patterson, G. R., \& Ge, X. (1995). It takes two to replicate: A mediational model for the impact of parents' stress on adolescent adjustment. Child Development, 66, 80-97. 
Cronbach, L. J., \& Meehl, P. E. (1955). Construct validity in psychological tests. Psychological Bulletin, 52, 281-302.

Davis-Kean, P. E. (2005). The influence of parent education and family income on child achievement: The indirect role of parental expectations and the home environment. Journal of Family Psychology, 19, 294-304.

Dubow, E. F. (1988). Aggressive behavior and peer social status of elementary school children. Aggressive Behavior, 14, 315-324.

Duncan, G. J., Brooks-Gunn, J., \& Klebanov, P. K. (1994). Economic deprivation and early childhood development. Child Development, 65, 296-318.

Eccles, J. S. (1993). School and family effects on the ontogeny of children's interests, self-perceptions, and activity choice. In J. Jacobs (Ed.), Nebraska Symposium on Motivation: Vol. 40. Developmental perspectives on motivation (pp. 145-208). Lincoln, NE: University of Nebraska Press.

Eccles, J., Templeton, J., Barber, B., \& Stone, M. (2003). Adolescence and emerging adulthood: The critical passage ways to adulthood. In M. H. Bornstein, L. Davidson, C. L. M. Keyes, \& K. A. Moore (Eds.), Well-being: Positive development across the life course (pp. 383-406). Mahwah, NJ: Erlbaum.

Eron, L. D., \& Huesmann, L. R. (1984). The relation of prosocial behavior to the development of aggression and psychopathology. Aggressive Behavior, 10, 201-211.

Eron, L. D., Walder, L. O., \& Lefkowitz, M. M. (1971). Learning of aggression in children. Boston: Little, Brown.

Feather, N. T., \& O'Brien, G. E. (1986). A longitudinal study of the effects of employment and unemployment on school-leavers. Journal of Occupational Psychology, 59, 121-144.

Feldt, T., Kokko, K., Kinnunen, U., \& Pulkkinen, L. (2005). The role of family background, school success, and career orientation in the development of sense of coherence. European Psychologist, 10, 298-308.

Fergusson, D. M., Horwood, L. J., \& Lynskey, M. T. (1997). The effects of unemployment on juvenile offending. Criminal Behaviour and Mental Health, 7, 49-68.

Hinshaw, S. (1992). Externalizing behavior problems and academic underachievement in childhood and adolescence: Causal relationships and underlying mechanisms. Psychological Bulletin, 111, 127-155.

Huesmann, L. R., Dubow, E. F., Eron, L. D., Boxer, P., Slegers, D., \& Miller, L. S. (2002, November). Continuity and discontinuity of aggressive behaviors across three generations. Paper presented at the meeting of the Society for Life History Research on Psychopathology, New York.

Huesmann, L. R., \& Eron, L. D. (1986). Television and the aggressive child: A cross-national comparison. Hillsdale, NJ: Erlbaum.

Huesmann, L. R., Eron, L. D., Lefkowitz, M. M., \& Walder, L. O. (1984). Stability of aggression over time and generations. Developmental Psychology, 20, 1120-1134.

Huesmann, L. R., Eron, L. D., \& Yarmel, P. W. (1987). Intellectual functioning and aggression. Journal of Personality and Social Psychology, 52, 232-240.

Huston, A., \& Ripke, M. (Eds.). (2006). Developmental contexts in middle childhood: Bridges to adolescence and adulthood. New York: Cambridge University Press.

Isomäki, H., \& Kukkonen, P. (1993). Toveriarviointi lasten sosiaalisen käyttäytymisen mittarina [Peer-nomination as a measure of children's social behavior]. Unpublished master's thesis, University of Jyväskylä, Jyväskylä, Finland.

Jahoda, M. (1981). Work, employment, and unemployment: Values, theories, and approaches in social research. American Psychologist, 36, 184-191.

Jastak, J. F., \& Jastak, S. (1978). The Wide Range Achievement Test manual of instructions (rev. ed.). Wilmington, DE: Jastak Associates.

Jimerson, S., Egeland, B., Sroufe, L. A., \& Carlson, B. (2000). A prospec- tive longitudinal study of high school dropouts examining multiple predictors across development. Journal of School Psychology, 38, 525549 .

Johnson, R. C., Nagoshi, C. T., Ahren, F. M., Wilson, J. R., DeFries, J. C., McClearn, G. E., et al. (1983). Family background, cognitive ability, and personality as predictors of educational and occupational attainment. Social Biology, 30, 86-100.

Kokko, K., \& Pulkkinen, L. (2000). Aggression in childhood and long-term unemployment in adulthood: A cycle of maladaptation and some protective factors. Developmental Psychology, 36, 463-472.

Kokko, K., \& Pulkkinen, L. (2005). Stability of aggressive behavior from childhood to middle age in women and men. Aggressive Behavior, 31, 485-497.

Kokko, K., Pulkkinen, L., \& Puustinen, M. (2000). Selection into longterm unemployment and its psychological consequences. International Journal of Behavioral Development, 24, 310-320.

Lefkowitz, M. M., Eron, L. D., Walder, L. O., \& Huesmann, L. R. (1977). Growing up to be violent: A longitudinal study of the development of aggression. New York: Pergamon.

Leventhal, T., \& Brooks-Gunn, J. (2000). The neighborhoods they live in: The effects of neighborhood residence on child and adolescent outcomes. Psychological Bulletin, 126, 309-337.

Luster, T., Rhoades, K., \& Haas, B. (1989). The relation between parental values and parenting behavior: A test of the Kohn hypothesis. Journal of Marriage and the Family, 51, 139-147.

Magnuson, K. A. (2004, July). The effect of mothers' returns to schooling on their children's academic achievement: Evidence from the ECLS-K. Paper presented at the meeting of the International Society for the Study of Behavioral Development, Ghent, Belgium.

McLoyd, V. C. (1998). Socioeconomic disadvantage and child development. American Psychologist, 53, 185-204.

Messick, S. (1995). Validity of psychological assessment: Validation of inferences from persons' responses and performances as scientific inquiry into score meaning. American Psychologist, 50, 741-749.

Morris, P., \& Michalopoulos, C. (2003). Findings from the SelfSufficiency Project: Effects on children and adolescents of a program that increased employment and income. Journal of Applied Developmental Psychology, 24, 201-239.

Piaget, J. (1965). The child's conception of the world. Totowa, NJ: Littlefield, Adams.

Pitkänen, L. (1969). A descriptive model of aggression and nonaggression with applications to children's behaviour. (Jyväskylä Studies in Education, Psychology and Social Research, Whole No. 19). Jyväskylä, Finland: University of Jyväskylä, Department of Psychology.

Pitkänen, T., Lyyra, A.-L., \& Pulkkinen, L. (2005). Age of onset of drinking and the use of alcohol in adulthood: A follow-up study from age 8-42 for females and males. Addiction, 100, 652-661.

Pulkkinen, L. (1982). Self-control and continuity from childhood to late adolescence: In B. P. Baltes \& O. G. Brim, Jr. (Eds.), Life-span development and behavior (Vol. 4, pp. 63-105). New York: Academic Press.

Pulkkinen, L. (1987). Offensive and defensive aggression in humans: A longitudinal perspective. Aggressive Behavior, 13, 197-212.

Pulkkinen, L. (1989). Predictability of the length of educational routes and the development of career lines. Scandinavian Journal of Educational Research, 33, 203-214.

Pulkkinen, L. (1996). Female and male personality styles: A typological and developmental analysis. Journal of Personality and Social Psychology, 70, 1288-1306.

Pulkkinen, L. (2001). Reveller or striver? How childhood self-control predicts adult social behavior. In A. C. Bohart \& D. J. Stipek (Eds.), Constructive and destructive behaviour: Implications for family, school, and society (pp. 167-185). Washington DC: American Psychological Association 
Pulkkinen, L. (2004). A longitudinal study on social development as an impetus for school reform toward an integrated school day. European Psychologist, 9, 125-141.

Pulkkinen, L. (2006). The Jyväskylä Longitudinal Study of Personality and Social Development. In L. Pulkkinen, J. Kaprio, \& R. J. Rose (Eds.), Socioemotional development and health from adolescence to adulthood (pp. 29-56). New York: Cambridge University Press.

Pulkkinen, L., Feldt, T., \& Kokko, K. (2005). Personality in young adulthood and functioning in middle age. In S. Willis \& M. Martin (Eds.), Middle adulthood: A lifespan perspective (pp. 99-141). Thousand Oaks, CA: Sage.

Pulkkinen, L., Feldt, T., \& Kokko, K. (2006). Adaptive behavior in childhood as an antecedent of psychological functioning in early middle age: Linkage via career orientation. Social Indicators Research, 77, 171-195.

Pulkkinen, L., Fyrstén, S., Kinnunen, U., Kinnunen, M.-L., Pitkänen, T., \& Kokko, K. (2003). 40+ Erään ikäluokan selviytymistarina $[40+\mathrm{A}$ successful transition to middle adulthood in a cohort of Finns] (Rep. No. 349). Jyväskylä, Finland: University of Jyväskylä, Department of Psychology.

Pulkkinen, L., Ohranen, M., \& Tolvanen, A. (1999). Personality antecedents of career orientation and stability among women compared to men. Journal of Vocational Behavior, 54, 37-58.

Sanford, M., Offord, D., McLeod, K., Boyle, M., Byrne, C., \& Hall, B. (1994). Pathways into the work force: Antecedents of school and work force status. Journal of the American Academy of Child and Adolescent Psychiatry, 33, 1036-1046.

Shiner, R. L., Masten, A. S., \& Roberts, J. M. (2003). Childhood personality foreshadows adult personality and life outcomes two decades later. Journal of Personality, 71, 1145-1170.

Singleton, L. C., \& Asher, S. R. (1977). Peer preferences and social interaction among third-grade children in an integrated school district. Journal of Educational Psychology, 69, 330-336.

Smith, J. R., Brooks-Gunn, J., \& Klebanov, P. K. (1997). Consequences of living in poverty for young children's cognitive and verbal ability and early school achievement. In G. J. Duncan \& J. Brooks-Gunn (Eds.),
Consequences of growing up poor (pp. 132-189). New York: Russell Sage Foundation.

Stevens, G., \& Hoisington, E. (1987). Occupational prestige and the 1980 U.S. labor force. Social Science Research, 6, 74-105.

Stipek, D. J. (1998). Pathways to constructive lives: The importance of early school success. In A. C. Bohart \& D. J. Stipek (Eds.), Constructive and destructive behaviors: Implications for family, school, \& society (pp. 291-315). Washington, DC: American Psychological Association.

Stipek, D., \& Ryan, R. (1997). Economically disadvantaged preschoolers: Ready to learn but further to go. Developmental Psychology, 33, 711723 .

Sullivan, E. T., Clark, W. W., \& Tiegs, E. W. (1957). California Short Form Test of Mental Maturity. Los Angeles: California Test Bureau.

Terry, R., \& Coie, J. D. (1991). A comparison of methods for defining sociometric status among children. Developmental Psychology, 27, 867880 .

Warner, W. L., Meeker, M., \& Eells, K. (1960). Social class in America. New York: Harcourt.

Warr, P. (1987). Work, unemployment and mental health. Oxford, England: Clarendon Press.

Warr, P., \& Jackson, P. (1985). Factors influencing the psychological impact of prolonged unemployment and re-employment. Psychological Medicine, 15, 795-807.

Weissberg, R. P., Caplan, M., \& Harwood, R. L. (1991). Promoting competent young people in competence-enhancing environments: A systems-based perspective on primary prevention. Journal of Consulting and Clinical Psychology, 59, 830-841.

Werner, E. E., \& Smith, R. S. (2001). Journeys from childhood to midlife: Risk, resilience, and recovery. Ithaca, NY: Cornell University Press.

Whitson, S. C., \& Keller, B. K. (2004). The influences of family of origin on career development: A review and analysis. The Counseling Psychologist, 32, 493-568.

Received August 29, 2005

Revision received April 24, 2006

Accepted May 23, 2006 